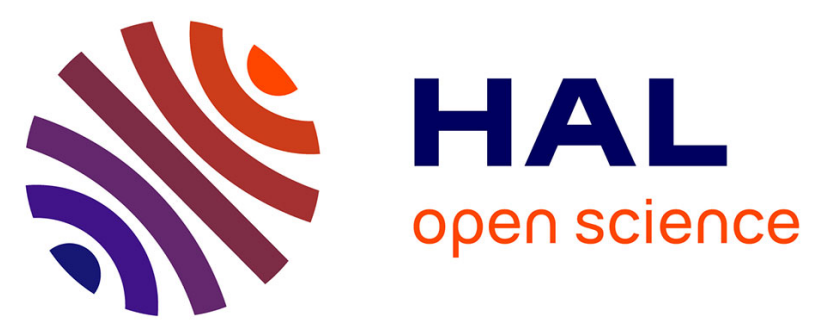

\title{
Identification of CTX-M15-, SHV-28-producing ST15 as an epidemic clone in the Copenhagen area using a semi-automated Rep-PCR typing assay
}

J. B. Nielsen, M. N. Skov, R. L. Jørgensen, O. Heltberg, D. S. Hansen, K. Schønning

\section{To cite this version:}

J. B. Nielsen, M. N. Skov, R. L. Jørgensen, O. Heltberg, D. S. Hansen, et al.. Identification of CTXM15-, SHV-28-producing ST15 as an epidemic clone in the Copenhagen area using a semi-automated Rep-PCR typing assay. European Journal of Clinical Microbiology and Infectious Diseases, 2011, 30 (6), pp.773-778. 10.1007/s10096-011-1153-x . hal-00661920

\section{HAL Id: hal-00661920 https://hal.science/hal-00661920}

Submitted on 21 Jan 2012

HAL is a multi-disciplinary open access archive for the deposit and dissemination of scientific research documents, whether they are published or not. The documents may come from teaching and research institutions in France or abroad, or from public or private research centers.
L'archive ouverte pluridisciplinaire HAL, est destinée au dépôt et à la diffusion de documents scientifiques de niveau recherche, publiés ou non, émanant des établissements d'enseignement et de recherche français ou étrangers, des laboratoires publics ou privés. 
Original article

Identification of CTX-M15, SHV-28 producing Klebsiella pneumoniae ST15 as an epidemic clone in the Copenhagen area using a semi-automated Rep-PCR typing assay.

Jesper Boye Nielsen ${ }^{1}$, Marianne Nielsine Skov², Rikke Lind Jørgensen ${ }^{1}$, Ole Heltberg ${ }^{3}$, Dennis Schrøder Hansen ${ }^{4}$, and Kristian Schønning ${ }^{1}$.

${ }^{1}$ Department of Clinical Microbiology 445, Hvidovre Hospital, DK-2650 Hvidovre, Denmark;

${ }^{2}$ Department of Clinical Microbiology, Odense University Hospital, DK-5000 Odense, Denmark;

${ }^{3}$ Department of Clinical Microbiology, Næstved Sygehus, DK-4700 Næstved, Denmark;

${ }^{4}$ Department of Clinical Microbiology, Hillerød Hospital, DK-3400 Hillerød, Denmark

Corresponding author:

Kristian Schønning, Department of Clinical Microbiology 445, Hvidovre Hospital, Kettegård Alle 30, DK-2650 Hvidovre, Denmark.

E-mail: kristian.schoenning@hvh.regionh.dk 


\section{Abstract:}

Rapid molecular typing methods can be a valuable aid in the investigation of suspected outbreaks. We used a semi-automated repetitive sequence-based PCR (Rep-PCR) typing assay and pulsed field gel electrophoresis (PFGE) to investigate the relationship between local Klebsiella pneumoniae (K. pneumoniae) producing extended spectrum $\beta$-lactamases (ESBL) and their relation to recognized Danish outbreak strains. PFGE and Rep-PCR produced similar clustering among isolates. Individual isolates from each cluster were further characterized by PCR amplification and sequencing of bla $a_{\mathrm{TEM}}, b / a_{\mathrm{SHV}}$ and bla $a_{\mathrm{CTX}-\mathrm{M}}$ and multilocus sequence typing (MLST). Thirtyfive out of 52 ESBL-producing $K$.

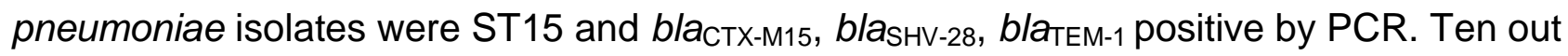
of 52 were ST16 and tested positive for bla $a_{\mathrm{CTX}-\mathrm{M} 15}, b_{\mathrm{SHV}^{-1}}$, bla $\mathrm{aTEM}-1_{1}$. Isolates from previously recognized hospital outbreaks were also ST15 and PCR positive for blaCTX-M15, bla $a_{\mathrm{SHV}-28}$, bla $a_{\mathrm{TEM}-1}$ and typed within the main cluster by both Rep-PCR and PFGE. In conclusion, K. pneumoniae ST15 containing bla $a_{\mathrm{CTX}-\mathrm{M} 15}$ and bla $\mathrm{SHV}_{\mathrm{SH} 28}$ constitutes an epidemic clone in the Copenhagen area and this clone can be rapidly recognized by semiautomated Rep-PCR.

Keywords: Rep-PCR, DiversiLab, pulsed-field gel electrophoresis (PFGE), extendedspectrum beta-lactamases (ESBL), multilocus sequence typing (MLST), CTX-M, Klebsiella. 


\section{Introduction}

Since 2000 most countries in Europe have experienced a rapid rise in Enterobacteriaceae harbouring extended spectrum $\beta$-lactamases (ESBLs) [1]. This increase in resistance can be largely explained by the dissemination of Escherichia coli (E. coli) and Klebsiella pneumoniae (K. pneumoniae) carrying CTX-M type $\beta$-lactamases [1,2]. These strains are increasingly isolated from community patients $[3,4]$ and at the same time hospitalassociated outbreaks with CTX-M carrying E. coli and K. pneumoniae strains have been well described [5-7].

To investigate the epidemiology of resistant bacteria, rapid typing methods can be a valuable aid. Semi-automated repetitive sequence-based PCR (Rep-PCR) typing methods offer the possibility to molecular type in excess of hundred isolates on a weekly basis [8-10]. At our institution (Department of Clinical Microbiology, Hvidovre Hospital, providing diagnostic service to four hospitals in the Copenhagen area), we have observed that the frequency of ESBL-producing $K$. pneumoniae in urinary cultures from inpatients had risen to $19.6 \%$ in October 2009. At the same time hospital-associated outbreaks with ESBL-producing K. pneumoniae were described at other hospitals in the eastern part of Denmark [11]. In the present study we wanted to investigate if ESBL-producing $K$. pneumoniae isolated at our institution were related and specifically related to other outbreak strains present in Denmark. Furthermore, we wanted to evaluate Rep-PCR as a rapid typing method for K. pneumoniae. In the present study we typed a strain collection of ESBL-producing K. pneumoniae isolated at our department in a 5 month period of 2008 using Rep-PCR and included strains from the recognized outbreaks in Denmark. To grossly assess the discriminatory power of this typing method we also included 8 fully susceptible isolates of $K$. pneumoniae from epidemiologically unrelated patients. We 
compared the results of Rep-PCR-based typing with pulsed field gel electrophoresis (PFGE) typing. We further characterized all clusters by multilocus sequence typing (MLST) and $\beta$-lactamase characterization by PCR and sequencing. The data obtained supports the usefulness of Rep-PCR as a typing tool in outbreak investigations.

\section{Material and methods:}

Strain collection:

The bacterial isolates studied were obtained from three different sources. First, a collection of consecutive clinical isolates of ESBL-producing K. pneumoniae isolated from routine diagnostics at the Department of Clinical Microbiology at Hvidovre Hospital between May and September 2008. Only a single isolate from a patient was included in the study collection. The isolates originated from urine samples $(\mathrm{N}=40)$, respiratory specimens $(\mathrm{N}=6)$, and wound swabs $(\mathrm{N}=6)$. ESBL production was determined using the combination disk method using cefotaxime and ceftazidime with and without clavulanic acid (NeoSensitabs, Rosco). The test was performed and interpreted using CLSI guideline criteria. Secondly, a collection of unrelated clinical isolates of $K$. pneumoniae fully susceptible to cephalosporins (cefpodoxime and cefuroxime) $(\mathrm{N}=8)$ was obtained. The isolates were randomly obtained on a single day among routine urinary cultures originating from hospitals. Finally, isolates from outbreaks of ESBL-producing K. pneumoniae from Hillerød Hospital, Denmark (N=2; isolated March 2007 and March 2008) and Nykøbing Falster Hospital, Denmark ( $N=2$, isolated August 2008) were included.

PFGE-typing: 
Bacterial DNA for PFGE was prepared by using the Salmonella standard protocol of Centers for Disease Control (CDC) PulseNet (http://www.cdc.gov/pulsenet/). Agarose plugs (chromosomal grade agarose from Biorad) containing DNA were digested with 50 units of the restriction enzyme Xbal (Amersham Life Science) for 4 hours. Electrophoresis was performed as described by the CDC PulseNet [12]. The CDC standard H9812 isolate was digested with $X b a l$ and used as the molecular size marker. Although not included in the CDC protocol we added ethidium bromide (Sigma, $10 \mathrm{mg}$ per $\mathrm{ml}$ ) to the gel and the TBE running buffer ( $5 \mu \mathrm{l}$ and $30 \mu \mathrm{l}$ respectively) in order to make especially the smallest bands visible. Gels were subsequently stained in aqueous ethidium bromide (Sigma, $2 \mu \mathrm{g}$ per $\mathrm{ml}$ ) and destained in distilled water for 15 minutes, respectively. Gels were photographed (using 300-nm UV light), analyzed, and interpreted by the use of BioNumerics (Applied Math, Belgium). All visible bands more than $33 \mathrm{~kb}$ in size were included in the interpretation of PFGE patterns and in the creation of a dendrogram. Criteria established by Tenover et al. [13] were used for identifying relatedness and to assign letters to the different isolates.

Rep-PCR-typing:

Bacterial isolates were grown overnight on Iso-Sensitest plates. Individual colonies were resuspended and DNA extracted using the Ultraclean Microbial DNA Isolation kit (MO BIO laboratories). Rep-PCR-typing was done using the DiversiLab Klebsiella Fingerprinting kit (bioMérieux) according to the instructions of the manufacturer. DiversiLab software was used to construct dendrograms and calculating percent similarity using Pearson correlation. 
MLST:

MLST was performed essentially as previously described by Diancourt et al. [14]. A modified protocol was used, which allows all 7 specific PCR amplifications to run simultaneously with the same PCR thermal profiles and with one set of sequence primers (http://www.pasteur.fr/recherche/genopole/PF8/mlst/Kpneumoniae.html). Sequencing was performed by Macrogen, Korea, and sequence- and data-analysis was carried out by use of CLC DNA workbench 5.2 (CLC Bio). Allele profile and sequence type (ST) were assigned at the website cited above.

$\beta$-lactamase-characterization:

ESBL-producing isolates that were typed by MLST were also tested for the presence of

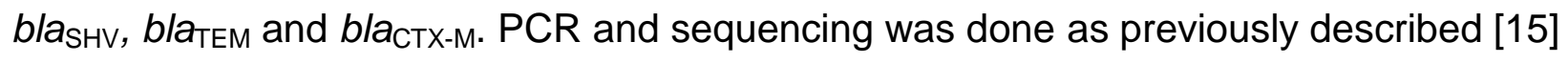
except for blasHV for which primers described by Nüesch-Inderbinen et al. [16], were used for both PCR and sequencing.

\section{Results:}

Reproducibility and discrimination of Rep-PCR typing:

To investigate the reproducibility of the Rep-PCR typing assay DNA from 13 isolates were extracted and Rep-PCR typed twice. Typing results from paired extractions showed more than $94 \%$ pairwise similarity for $11 / 13$ isolates. Results from the two remaining isolates showed only $83.0 \%$ and $86.7 \%$ similarity; the reason for this discrepancy is unclear, however, a third extraction of the two samples typed with 97.5 and $91.6 \%$ similarity with one of the earlier replicates. 
To assess the discriminatory power of Rep-PCR typing 8 epidemiologically unrelated ESBL-negative isolates of $K$. pneumoniae were typed. Pairwise similarities between these isolates were between $52.8 \%$ and $82.7 \%$. Thus, using a cut-off between $83 \%$ and $92 \%$ in similarity would provide acceptable reproducibility and discrimination.

\section{Comparison of Rep-PCR typing with PFGE typing:}

PFGE is well established as a typing method of $K$. pneumoniae [17]. To investigate if RepPCR typing could provide results in congruence with PFGE typing, 64 K. pneumoniae isolates were typed using both PFGE and Rep-PCR typing. Using PFGE-typing all isolates were typable. Results showed that the isolates clustered into 19 different groups; the two largest clusters comprised 35 and 10 isolates, respectively (cf. Fig. 1). Close inspection of the dendrogram produced from the PFGE results showed that several subtypes could be distinguished within the largest clusters.

Rep-PCR typing displayed similar results. Using a similarity cutoff of $91 \%$ Rep-PCR identified 20 different clusters. All individual isolates were assigned the same clusters using both methods with the following exceptions: Isolate 24 and 45 were recognized as related by Rep-PCR and isolate 46 was recognized as an individual type by Rep-PCR but not by PFGE (cf. Fig. 1 and Fig. 2). Furthermore, Rep-PCR divided the second largest cluster identified by PFGE into two apparent clusters: Rep-types 8 and 9 (cf. Fig. 2). However, pairwise similarity between isolate 55 (cluster 8) and all other isolates in cluster 9 and between isolate 56 (cluster 9) and all other isolates in cluster 8 were $>91 \%$, suggesting the overall relatedness between the two apparent clusters. Individual subtypes present in the two main clusters with PFGE-typing were not reproduced by Rep-PCR. The overall agreement between the two methods was high with 
62/64 (97\%) isolates being assigned to identical clusters, if accepting that Rep-PCR tended to subtype the second largest clusters by PFGE into two clusters.

\section{MLST:}

In order to further investigate the relationship between clusters and isolates yielding discrepant results with the two typing methods, MLST was performed for representative isolates from each cluster that was reproduced by both methods and for isolates with discrepant results. All 8 epidemiologically unrelated ESBL-negative K. pneumoniae isolates had different sequence types (STs). MLST generally supported the typing results obtained by PFGE and Rep-PCR. Three isolates (36 (Rep-type 9), 42 and 69 (both Reptype 8)) typed by MLST and belonging to the second largest cluster identified by PFGE were all ST16 supporting the division made by PFGE and the relatedness of the isolates. Isolates 24 and 45 (both Rep-type 1, cf. Fig. 1) were both ST45 supporting the division made here by Rep-PCR. For isolate 46 we were only able to achieve readable sequence for 6 alleles despite multiple amplification attempts of the last allele. These 6 alleles were all the same as for ST15 supporting the division made by PFGE. With the exceptions that Rep-PCR tended to subtype ST16 isolates and that isolate 46 was assigned an unique type by Rep-PCR but belonged at least to the same clonal complex as the main cluster, representatives of the individual Rep-PCR types all yielded unique STs by MLST. Thus, both Rep-PCR and PFGE-typing yielded very congruent results with MLST.

Molecular epidemiology of ESBL-producing K. pneumoniae:

In order to further describe the molecular epidemiology of ESBL-producing K. pneumoniae PCR-amplification and sequencing of bla $a_{\mathrm{CTX}-\mathrm{M}}, b_{\mathrm{SHV}^{-}}$and $b / a_{\mathrm{TEM}}-\beta$-lactamases were done 
for representative isolates of the individual clusters. All ESBL producing isolates except two (i.e. 54 out of 56) were positive for blactX-M15. The two exceptions were isolate 41 that was positive for bla which a blasHV-12 was identified. For the main clusters (Rep-type 5 and 8/9), characterization of blasнv and blaтем-type $\beta$-lactamases of representative isolates was undertaken. For Rep-type 8 and 9, all 3 representatives characterized were blactX-M15, bla $a_{\mathrm{SHV}-1}$ and $b / a_{\mathrm{TEM}-1}$ positive. For Rep-type 5, six representatives characterized were all bla $a_{\mathrm{CTX}-\mathrm{M} 15}, b / a_{\mathrm{SHV}-28}, b / a_{\mathrm{TEM}-1}-$ positive. These included strains from the Hillerød (isolate H17) and Nykøbing (isolate N3) outbreaks. These results indicate the relatedness between outbreak strains from previous outbreaks and the current epidemic CTX-M15-, SHV-28producing of $K$. pneumoniae ST15 strain found at our institution.

\section{Discussion:}

An ideal typing method for outbreak investigation provides rapid typing results at a low cost, is reproducible and stable, discriminatory and highly standardized and definitive with a reporting format that can be compared between laboratories [18]. Rep-PCR typing has the promise to fulfil most of these needs.

Rep-PCR typing is a band-pattern generating typing method. A general problem with these methods is the need of establishing a cut off level for clustering. In the present study we tried to solve this problem by first assessing the reproducibility of the method. Two different DNA extractions from the same isolate should give identical results. Using a similarity cut-off of $94 \%$ this could be achieved for $12 / 13$ samples, which was considered acceptable. The reasons for the discrepant results of the last sample are unclear but reinforce the need for strict standardization of Rep-PCR for the method to yield 
reproducible and definitive typing results. Next, we typed epidemiologically unrelated isolates that were shown by MLST to belong to different STs. None of these isolates displayed a pairwise similarity above $83 \%$. Finally, we compared the results of Rep-PCR typing with PFGE and found that the two methods yielded congruent results using a similarity index for Rep-PCR typing of $91 \%$. The clusters obtained using this cut-off were generally supported by MLST. We support the recommendation that prior evaluation to establish a cut-off for clustering is necessary before performing typing studies [19].

When comparing results from PFGE, Rep-PCR and MLST, PFGE seemed to be the most discriminatory method identifying most subtypes and MLST appeared to be the least discriminatory yielding identical STs across clusters identified by Rep-PCR and PFGE. Compared to both PFGE and Rep-PCR, MLST has the advantage of an internetaccessible database ensuring a standardized nomenclature.

In the present study, we used semi-automated Rep-PCR to cluster related isolates before selected isolates were chosen for extensive and costly characterization by MLST and $\beta$-lactamase identification. Used for this purpose it is essential that strains that cluster by the primary typing method are indeed related by the second, i.e. that the primary typing method is the most discriminatory. Thus, Rep-PCR can be used as a rapid and less costly typing method than MLST to cluster K. pneumoniae and to select isolates for further analysis, e.g. $\beta$-lactamase characterization and MLST. Used in this way, we have established that two different lineages of ESBL-producing K. pneumoniae, CTX-M15- and SHV-28-producing ST15 and CTX-M15- and SHV-1-producing ST16, are prevalent in the Copenhagen area and may contribute significantly to the observed increase in resistant $K$. pneumoniae observed in our institution and in Denmark [11]. Using a similar approach Damjanova et al. [7] reported CTX-M15-producing K. pneumoniae ST15 to be the most 
prevalent ESBL-producing lineage in Hungary associated with nosocomial spread. Our study documents the dissemination of this lineage in different regions of Europe and demonstrates the value of MLST as a definitive typing method with an internationally accepted nomenclature.

\section{Acknowledgement:}

The authors gratefully acknowledge support from bioMerieux for providing access to the Agilent 2100 bioanalyzer.

\section{Transparency Declaration:}

This work was supported by Fondation Idella (Grants 3.3.5.-2007 and 3.3.5/2008/II to K.S.). All authors declare that they do not have any commercial interest or associations that poses a conflict of interest with regard to this article.

\section{References:}

1. Coque TM, Baquero F, Canton R (2008) Increasing prevalence of ESBLproducing Enterobacteriaceae in Europe. Euro Surveil 13:pii19044.

2. Livermore DM, Canton R, Gniadkowski M, Nordmann P, Rossolini GM, Arlet G, Ayala J, Coque TM, Kern-Zdanowicz, Luzzaro F, Poirel L, Woodford N (2007) CTX-M: changing the face of ESBLs in Europe. J Antimicrob Chemother 59:165-174. 
3. Pitout JDD, Nordmann P, Laupland KB, Poirel L (2005) Emergence of Enterobacteriaceae producing extended-spectrum $\beta$-lactamases (ESBLs) in the community. J Antimicrob Chemother 56:52-59.

4. Valverde A, Coque TM, Sánchez-Moreno MP, Rollán A, Baquero F, Cantón R (2004) Dramatic increase in prevalence of faecal carriage of extendedspectrum $\beta$-lactamase-producing Enterobacteriaceae during nonoutbreak situations in Spain. J Clin Microbiol 42:4769-4775.

5. Lytsy B, Sandegren L, Tano E, Torell E, Andersson DI, Melhus A (2008) The first major extended-spectrum beta-lactamase outbreak in Scandinavia was caused by clonal spread of a multiresistant Klebsiella pneumoniae producing CTX-M-15. APMIS 116:302-308.

6. Naseer U, Haldorsen B, Tofteland S, Hegstad K, Scheutz F, Simonsen GS, Sundsfjord A, Norwegian ESBL study group (2009) Molecular characterization of CTX-M-15-producing clinical isolates of Escherichia coli reveals the spread of multidrug-resistant ST131 (O25:H4) and ST964 (O102:H6) strains in Norway. APMIS 117:526-536.

7. Damjanova I, Tóth Á, Pászti J, Hajbel-Vékony G, Jakab M, Berta J, Milch H, Füzi M. Expansion and countrywide dissemination of ST11, ST15 and ST147 ciprofloxacin-resistant CTX-M-15-type $\beta$-lactamase-producing Klebsiella pneumoniae epidemic clones in Hungary in 2005-the new 'MRSAs' (2008) J Antimicrob Chemother 62:978-985. 
8. Healy M, Huong J, Bittner T, Lising M, Frye S, Raza S, Schrock R, Manry J, Renwick A, Nieto R, Woods C, Versalovic J, Lupski JR (2005) Microbial DNA Typing by Automated Repetitive-Sequence-Based PCR. J Clin Microbiol 43:199-207.

9. Pitout JDD, Campbell L, Church DL, Wang PW, Guttman DS, Gregson DB (2009) Using a Commercial DiversiLab Semiautomated Repetitive SequenceBased PCR Typing Technique for Identification of Escherichia coli Clone ST131 Producing CTX-M-15. J Clin Microbiol 47:1212-1215.

10. Lau SH, Cheesborough J, Kaufmann ME, Woodford N, Dodgson AR, Dodgson KJ, Bolton EJ, Fox AJ, Upton M (2010) Rapid identification of uropathogenic Escherichia coli of the O25:H4-ST131 clonal lineage using the DiversiLab repetitive sequence-based PCR system. Clin Microbiol Infect 16:232-237.

11. Hammerum AM, Jensen US, Olsen SS, Skjøt-Rasmussen L, Frimodt-Møller N, DANRES Studygroup (2008). Increased occurrence of resistant Klebsiella pneumoniae in Danish hospitals. DANMAP 2008: 21-22. http://www.danmap.org/pdfFiles/Danmap_2008.pdf 
12. Ribot EM, Fair MA, Gautom R, Cameron DN, Hunter SB, Swaminathan B, Barrett TJ (2006) Standardization of pulsed-field gel electrophoresis of Escherichia coli O157:H7, Salmonella, and Shigella for PulseNet. Foodborne pathogens and disease 3:59-67.

13. Tenover FC, Arbeit RD, Goering RV, Mickelsen PA, Murray BE, Persing DH, Swaminathan B (1995) Interpreting chromosomal DNA restriction patterns produced by pulsed-field gel electrophoresis: Criteria for bacterial strain typing. J Clin Microbiol 33:2233-2239.

14. Diancourt L, Passet V, Verhoef J, Grimont PAD, Brisse S (2005) Multilocus Sequence Typing of Klebsiella pneumoniae Nosocomial Isolates. J Clin Microbiol 43:4178-4182.

15. Jørgensen RL, Nielsen JB, Friis-Møller A, Fjeldsøe-Nielsen H, Schønning K (2010) Prevalence and molecular characterization of clinical isolates of Escherichia coli expressing an AmpC phenotype. J Antimicrob Chemother 65:460-464. 
16. Nüesch-Inderbinen MT, Hächler H, Kayser FH (1996) Detection of genes coding for extended-spectrum SHV beta-lactamases in clinical isolates by a molecular genetic method, and comparison of the E-test. Eur J Clin Microbiol Infect Dis 15:398-402.

17. Vimont S, Mnif B, Fevre C, Brissé S (2008) Comparison of PFGE and multilocus sequence typing for analysis Klebsiella pneumoniae isolates. J Med Microbiol 57:1308-1310.

18. van Belkum A, Tassios PT, Dijkshoorn L, Haaeggman S, Cookson B, Fry NK, Fussing V, Green J, Feil E, Gerner-Smidt P, Brisse S, Struelens M; European Society of Clinical Microbiology and Infectious Diseases (ESCMID) Study Group on Epidemiological Markers (ESGEM) (2007) Guidelines for the validation and application of typing methods for use in bacterial epidemiology. Clin Microbiol Infect 13(Suppl. 3):1-46.

19. Ross TL, Merz WG, Farkosh M, Carroll KC (2005) Comparison of an automated repetitive sequence-based PCR microbial typing system to pulsedfield gel electrophoresis for analysis of outbreaks of methicillin-resistant Staphylococcus aureus. J Clin Microbiol 43:5642-5647. 


\section{Legends for figures:}

Figure 1: PFGE cluster analysis of macrorestriction profiles of $64 \mathrm{~K}$. pneumoniae isolates including outbreak strains from Hillerød ( $\mathrm{H} 17$ and $\mathrm{H} 21)$ and Nykøbing (N3 and N4), and 8 ESBL negative isolates (NEG1-NEG8). Black horizontal lines separate different clusters. MLST was performed on at least one isolate from each cluster and sequence types (ST) for these isolates are also shown.

Figure 2: Repetitive sequence-based PCR (Rep-PCR) profile analysis; dendrogram showing similarity scores between $64 \mathrm{~K}$. pneumoniae isolates with virtual gel-images of Rep-PCR fragments. Assigned Rep-PCR groups and pulsed-field gel electrophoresis (PFGE) groups are also indicated. SHV- and CTX-M-beta-lactamase characterization, and sequence types (ST) of selected representatives from each cluster are also shown. The red vertical line shows cut-off and black horizontal lines separate the different clusters. 